Mauro Giovanni Carta $\cdot$ Alberto Carlo Altamura $\cdot$ Maria Carolina Hardoy $\cdot$ Federica Pinna Stefania Medda $\cdot$ Liliana Dell'Osso $\cdot$ Bernardo Carpiniello $\cdot$ Jules Angst

\title{
Is recurrent brief depression an expression of mood spectrum disorders in young people?
}

\section{Results of a large community sample}

Received: 26 June 2002 / Accepted: 31 March 2003

Abstract The clinical relevance of Recurrent Brief Depression (RBD) has not received sufficient attention to date and continues to represent a controversial issue. The present study was carried out in a community sample to evaluate the lifetime prevalence of RDB, the degree of comorbidity, as well as possible risk factors. Subjects from a community survey in Sardinia (Italy) were randomly selected from registers of a rural, an urban and a mining area ( $n=1040,461$ males, 579 females). Interviews were carried out by physicians using the Italian version of the Composite International Diagnostic Interview Simplified which had been modified for the purpose of this study. Lifetime prevalence of RBD was $7.6 \% ; 5.8 \%$ in males, $9 \%$ in females. Subjects aged 18 to 24 years presented higher frequencies (13.8\%, OR 2.2) than those aged 25 or over. Comorbidity with Major Depression was particularly frequent. RBD was furthermore associated with suicide attempts and substance abuse, thereby constituting an effective health problem. Further epidemiological and clinical studies of RBD are warranted in order to develop specific treatments and prevention strategies.

Prof. M. G. Carta (西) · M. C. Hardoy · F. Pinna •

S. Medda $\cdot$ B. Carpiniello

Division of Psychiatry

Department of Public Health

University of Cagliari

Via Liguria 13

09127 Cagliari, Italy

Tel.: +39-070/42760

$+39-070 / 272748$

$+39-335 / 499994$

Fax: + 39-070/496295

E-Mail:mgcarta@tiscali.it

A. C. Altamura

University of Milan, Italy

M. C. Hardoy · L. Dell'Osso

Department of Psychiatry

Neurobiology, Pharmacology and Biotechnology

University of Pisa, Italy

J. Angst

Zurich University Psychiatric Hospital

Zurich, Switzerland
Key words recurrent brief depression $\cdot \operatorname{mood}$ disorders $\cdot$ community survey $\cdot$ suicide $\cdot$ substance abuse

\section{Introduction}

To date, the clinical and epidemiological relevance of Recurrent Brief Depression (RBD) has not been adequately recognized and no large scale investigation of the disorder has been undertaken. Although findings from three community surveys have reported that RDB is not uncommon in the general population of Zurich (Angst 1994a, b), Mainz (Maier et al. 1992) and Cagliari (Altamura et al. 1995) and the World Health Organization (WHO 1992) study on psychiatric diseases in general medical practice has shown a relevant frequency of RBD in all contexts studied (Sartorius et al. 1993), no recent epidemiological surveys on this topic have been performed.

The study performed by Altamura (Altamura et al. 1995 ) in the same area examined in the present study using identical diagnostic tools seemed to indicate a higher frequency of RBD in young adults.

The aim of this study was to verify in a large sample of the general population of one of the Italian regions (Sardinia) the hypothesis of a potentially increased risk of RBD in the young and to clarify several public health aspects of RBD. Particular attention was paid to the report of an increased number of suicide attempts among young adults which was apparently associated to depressive disorders and substance abuse (Wetzel et al. 1987; Carlson etal. 1991), conditions often observed concomitant to RBD (Angst 1994b). Moreover, recent studies indicate the symptomatic expression of depression in young people (Wallace and Pfohl 1995); the aim of this study therefore was to investigate the possibility that RBD may represent an expression of mood spectrum disorders in young people. 


\section{Method}

\section{Design of the study}

A community cross sectional one phase survey was performed. All subjects selected were initially contacted by letter or phone and were asked to participate in the study.

\section{Sample}

The sample examined had previously taken part in a large community survey (Carta etal. 2002) and was made up of 1040 subjects; 461 males and 579 females; 393 were resident in the town of Cagliari (Italy), 344 in 4 rural villages and 303 in 2 mining villages. The urban sub-sample was extracted by randomization techniques $(1 / 100)$ subsequent to stratification according to age and sex, from the registrar's records of four districts in Cagliari; the rural sample was extracted in a similar manner on the basis of a randomization ratio of $1 / 10$. The sample from the mining area was made up of subjects who continued to reside in the area and who had been included in the sample evaluated in a previous community survey carried out ten years previously (Carta et al. 1991), together with a sample selected by randomization techniques, subsequent to stratification according to age and sex among resident subjects aged from 18 to 28 years. A further group was extracted from subjects over the age of 28 who had moved to the area in the period between the two studies.

This study forms part of a larger research project on mental health in Sardinia (Carta et al. 2002). The three areas were chosen to represent the three main social and economic sectors in the region (industry and services in towns, farming and mining in rural areas).

Throughout the three Sardinian areas concerned, $79.2 \%$ of all subjects identified (1313 subjects) agreed to take part in the study, while $164(12.5 \%)$ refused to participate and $109(8.3 \%)$ could not be traced; with respect to stratification variables applied, the final sample obtained was completely similar to the population of origin (Carta et al. 2002).

\section{Interview}

Personal interviews were conducted by specifically trained physicians. Two standardized forms were used to acquire information concerning: demographic data, state of health (general medical conditions), use of drugs and use of social and health services both over the last year and during the 2 weeks prior to the interviews. Psychiatric diagnosis was performed using a modified Italian version (Carta et al. 1995) of the CIDIS (Composite International Diagnostic Interview Simplified, Kovess et al. 1996; Kovess et al. 2001). The CIDI interview
(Robins et al. 1988) in its various versions currently represents the most widely used diagnostic tool in psychiatric epidemiological community surveys (Horwarth and Weissman 1995). The modified version, CIDIS, is a highly structured interview made up of 5 sections which investigate respectively: 1) Somatoform Disorders and General Medical Conditions; 2) Anxiety Disorders; 3) Depressive Disorders; 3) Alcohol and Substance Abuse; 5) Eating Disorders. The computer elaboration of data obtained enables prevalence of a series of psychiatric disorders according to both ICD-10 (WHO 1992) and DSM-IV (APA 1994) diagnostic criteria to be calculated.

A section on RBD, not present in the original interview, was incorporated into the Italian version of CIDIS; this section concerns three specific items as an appendix to questions regarding depression; the first two refer to the presence of episodes, their duration and frequency, while the third is addressed only to females and is intended to exclude brief depressive episodes linked to the menstrual cycle. A diagnosis of RBD was formulated if all the above conditions had been met and a monthly recurrence of the disorder had been present for at least 1 year (Altamura et al. 1995). The three specific items were extrapolated from the SCAN interview (Wing et al. 1990) and represent the section of the latter interview covering RBD. In cases where presence of the disorder was ascertained, the eventual seeking of medical help (from general practitioner, psychiatrist or other), the taking of drugs and whether life style had been affected were assessed.

Diagnoses made on the basis of ICD-10 criteria (WHO 1992) were evaluated for the purpose of this study in terms of Lifetime Prevalence; Lifetime Substance Related Abuse (SRA) was not diagnosed according to ICD-10 but was based on patient's reporting use of drugs (excluding cannabis and its derivates) more than 5 times.

This diagnosis had been introduced in the original version of the CIDIS interview and used in trials performed using the above tool (Kovess et al. 1996). The item was not modified in our version as one of the aims of the project was to compare the mental health status of Sardinians resident in Sardinia with those of Sardinian emigrants in Paris (Carta et al.2002). The above diagnosis is wider ranging than both the concept of Harmful Use (ICD-10, WHO 1992) which involves the observation of clear-cut psychological or physical damage, and the concept of Substance Abuse (DSM-IV, APA 1994) which entails being incapable of carrying out tasks at work, use of drugs in risky situations, as well as recurrent legal problems caused by substance use or abuse and social problems. The so-called new means of abuse among young people (e.g. "Saturday night fever") often remain asymptomatic over long periods. For this reason, and in consideration of the aims of the present study, diagnosis would appear to be appropriate.

Reliability (test retest) and Validity (versus SCAN administered by psychiatrists as a Golden Standard) study of CIDIS Italian version was carried out on a sample of 
outpatients of the Division of Psychiatry of the University of Cagliari and findings were published (Carta et al. 1994). The reliability of the instrument was good, with a $\mathrm{K}$ mean of 0.94 for the section on depressive disorders and 0.92 for the sub-section concerning RBD: compared to SCAN interview diagnostic accuracy for RBD demonstrated a sensitivity of 0.67 and specificity of 0.94 (the questions in the sub-section were identical and were administered by a trained psychiatrist in an unstructured manner at SCAN interview, while CIDIS interview required administration in a structured manner by physicians with psychiatric experience trained in the use of CIDIS).

\section{Data analysis}

Lifetime prevalence of RBD and the Odds Ratio association (univariate analysis) of RBD (dependent variable) were calculated for females vs. males and in various agegroups, using 18-24 range as the reference category. The association of RBD with the main diagnoses deriving from CIDIS interview were also calculated using the Odds Ratio. Statistical significance was calculated using the X2 test in $2 \times 2$ tables. Odds Ratio confidence intervals were calculated through application of the method of Miettinen (1974).

A positive family history embraced first and second degree relatives. The following diagnoses were assessed: Major Depression, Bipolar Disorder, Substance Related Abuse, Suicide Attempts.

\section{Results}

Overall lifetime prevalence of RBD was 7.6\% $(n=79)$, lifetime prevalence in males was $5.8 \%$ and in females $9 \%$; no statistically significant differences were observed with respect to sex. Table 1 illustrates a comparison in lifetime prevalence of RBD between the four community surveys present in the literature. Lifetime prevalence according to age and sex with specific Odds Ratio and $95 \%$ Confidence intervals are shown in Table 2 ; subjects aged from 18 to 24 years presented higher frequencies $(13.8 \%)$ and were at statistically significant variance with respect to age groups $45-64,>65$ and the other groups taken into consideration (CI 95\% $1.31-3.83$, OR 2.2, $\mathrm{P}<0.001$ ). Table 2 reports findings of comorbidity: Major Depression (MD), Dysthymia, So-

Table 1 Lifetime RBD in 4 community surveys

\begin{tabular}{lll}
\hline Author & Site & \% Prevalence \\
\hline Angst (1994a, b) & Zurich & 14.1 \\
Maier et al. (1992) & Mainz & 10.0 \\
Altamura et al. (1995) & Cagliari & 6.9 \\
Carta et al. (2002) & Sardinia & 7.6 \\
\hline
\end{tabular}

Table 2 Lifetime prevalence of RBD according to age and sex

\begin{tabular}{lrllll}
\hline & Prevalence \% & $\begin{array}{l}\text { Odds } \\
\text { Ratio }\end{array}$ & $\begin{array}{l}95 \% \\
\text { Confidence } \\
\text { Intervals }\end{array}$ & $\begin{array}{l}\text { Chi } \\
\text { square }\end{array}$ & $P$ \\
\hline Female & $9.0(n=52)$ & 1.6 & $0.82-2.84$ & 3.1 & 0.08 \\
Male & $5.8(n=27)$ & & & & \\
age 18-24 & $13.8(n=20)$ & $2.2^{*}$ & $1.31-3.83^{*}$ & $8.3^{*}$ & $0.01^{*}$ \\
age 25-44 & $8.8(n=31)$ & $0.6^{* *}$ & $0.30-1.17^{* *}$ & $2.2^{* *}$ & $0.13^{* *}$ \\
age 45-64 & $5.1(n=16)$ & $0.3^{* *}$ & $0.04-0.65^{* *}$ & $9.8^{* *}$ & $0.001^{* *}$ \\
age $>64$ & $5.2(n=12)$ & $0.3^{* *}$ & $0.12-0.72^{* *}$ & $7.2^{* *}$ & $0.007^{* *}$ \\
\hline
\end{tabular}

*age $18-24$ versus age $>25$; ** versus age $18-24$

cial Phobia (SP), Panic Attack Disorder (PAD), Substance Related Abuse (SRA) and Suicide Attempts (SA) were strictly associated with RBD, while no association was revealed for Generalized Anxiety Disorder (GAD) and Bulimia. In all 3 cases of RBD with Suicide Attempts, comorbidity with Major Depression was present. Mean age at onset of the major depressive episode was $27.2 \pm 11.0$ years in subjects affected by concomitant $\mathrm{RDB}$ and $33.8 \pm 13.8$ years in subjects without $\mathrm{RBD}$ $(\mathrm{F}=6.6,139 \mathrm{DF}, \mathrm{P}=0.012)$. Lifetime diagnosis of at least one psychiatric disorder according to ICD-10 was observed in 56 subjects with RBD (70.9\%). Subjects with $\mathrm{RBD}$ presented a positive family history for Major Depression $27.8 \%(n=22)$, Bipolar Disorder $2.5 \%(n=2)$, Substance Related Abuse 5\% $(n=4)$, Suicide Attempts $1.3 \%(\mathrm{n}=1)$.

\section{Discussion}

The present study seems to confirm the relevance of $\mathrm{RBD}$ in samples obtained on a community basis. As reported in Table 1, lifetime prevalence of RBD in our sample was within the range of findings of previous community surveys carried out by Angst $(1994 a, b)$ in Zurich, Maier et al. (1992) in Mainz and Altamura et al. (1995) in Cagliari. The Altamura survey, carried out using the same diagnostic instrument, indicated an increased risk among lower age groups; findings from the present study confirm this trend and show a higher risk for young people between the ages of 18 and 24. This finding is highly significant due to the fact that lifetime prevalence of the disorder, expressing a cumulative value obtained over the years, was calculated; if incidence of the disorder had been the same throughout the various age groups, lifetime prevalence should have increased rather than decreased with age.

Several hypotheses may be put forward to explain this finding: first, aged subjects may have difficulty in recalling a past disorder such as RDB; this would lead to a decrease in lifetime prevalence in old age respect to "real" calculation of the disorder. However, whether or not past episodes had been forgotten by aged subjects, if incidence had been constant throughout the various age 
Table 3 Comorbidity between RBD, other ICD-10 (WHO, 1992) psychiatric diagnosis, substance related abuse and suicide attempts

\begin{tabular}{lccllll}
\hline Diagnosis & $\begin{array}{l}\text { \% Lifetime } \\
\text { prevalence } \\
\text { in subjects } \\
\text { with RBD (n) } \\
\%=\mathrm{n} / 79\end{array}$ & $\begin{array}{l}\text { \% Lifetime } \\
\text { prevalence } \\
\text { in all sample }(\mathrm{n})\end{array}$ & $\begin{array}{l}\text { Odds } \\
\text { Ratio }\end{array}$ & $\begin{array}{l}\text { 95\% } \\
\text { Confidence } \\
\text { intervals }\end{array}$ & $\mathrm{P}$ & $\begin{array}{l}\text { Chi } \\
\text { Square }\end{array}$ \\
\hline MD & $44.3(35)$ & $13.5(140)$ & 6.5 & $4.14 / 10.18$ & 0.0001 & 66.9 \\
Dysthymia & $11.3(9)$ & $4.3(45)$ & 3.3 & $1.48 / 7.34$ & 0.003 & 8.5 \\
SP & $7.5(6)$ & $2.2(23)$ & 4.6 & $1.70 / 12.40$ & 0.003 & 8.9 \\
GAD & $13.9(11)$ & $11.3(118)$ & 1.3 & $0.50 / 3.36$ & 0.571 & 0.3 \\
PAD & $8.8(7)$ & $2.8(30)$ & 4.0 & $1.60 / 9.98$ & 0.003 & 8.7 \\
Bulimia & $1.3(1)$ & $0.5(5)$ & 3.1 & $0.02 / 476.3$ & 0.839 & 3.1 \\
SRA & $5.0(4)$ & $1.0(11)$ & 7.3 & $2.04 / 26.05$ & 0.002 & 9.3 \\
SA & $3.7(3)$ & $1.0(10)$ & 5.4 & $1.14 / 25.48$ & 0.032 & 4.6 \\
\hline
\end{tabular}

MD Major Depression; SP Social Phobia; GAD Generalized Anxiety Disorder; PAD Panic Attack Disorder; SRD Substance Related Abuse; $S A$ Suicide Attempts groups, no increase of prevalence would have been observed among young people. A more plausible interpretation may be that such a finding is the result of an effectively higher risk of RDB among the young, or even suggest a recent increase of $\mathrm{RDB}$ in young people.

The latter hypothesis is in agreement with the recently demonstrated time trend illustrating an increase in depressive disorders, together with the progressive decrease of age of onset of depressive disorders reported in recent epidemiological studies (Horwath and Weissman 1995). Accordingly, the trend revealed by transversal studies was investigated to determine whether it was due to an actual cohort effect or was the result of confounding factors such as response-biased memory and the use of diagnostic assessment procedures insufficiently adapted for identifying clinically relevant symptoms of depression in the elderly not meeting the criteria for major depression (Wittchen 1993). An accurate analysis of time trends obtained in various studies led to the identification of an actual recall bias and to the conclusion that true lifetime prevalence is much higher than estimated by cross-sectional surveys (Simon et al. 1995). However, the increase observed in depression among adolescents born after the second world war is considerable and the presence of recall bias cannot suffice to justify a phenomenon of this capacity (Kessler and Walters 1998; Hasin and Link 1988). Moreover, the trend has been partially confirmed in several studies repeated at a later date (Horwath and Weissman 1995).

The present study is characterized by the lack of presence of a gender effect with no statistically significant differences between males and females. This finding may simply be due to the low power of the study.

It should also be considered that the onset is earlier in comorbid than in pure MD. Several studies maintain that the recently demonstrated increase of depression in young adults may only apply to depression secondary to anxiety disorders while the prevalence of pure and primary depression has remained unchanged (Kessler and Walters 1998). In our study, however, RBD was associated with SP and PAD but not with GAD. It should also be underlined that an inverse relationship was illustrated between age at onset of major depression and risk of depression in first degree relatives (Weissman et al. 1984). Likewise, a vast Japanese study demonstrated a decrease in age at onset in youngsters from two families at high risk for unipolar disorders and for uni- and bipolar disorders, respectively (Ohara et al. 1998). The early onset of depressive disorders would seem therefore to be associated mainly to familial forms of mood disorders, which our findings indicate as being the category of disorders to which RBD belongs.

On the basis of the profile of comorbidity and degree of familiarity demonstrated in the present study and confirmed by previous research performed by Montgomery et al. (1989), Angst (1994a, b), Angst and DoblerMikola (1994), RBD would appear to meet requirements for collocation in the spectrum of mood disorders. This recurrent disorder does not seem to act merely as a marker of severity of depressive disorders (suicide attempts appear to be more frequent among patients with comorbid disorders) but rather may represent a specific means of expression of depression in young people.

It is generally acknowledged that the diagnosis of mood disorders in adolescents is rather problematical; this difficulty has at times been associated to an increased risk of suicide and substance abuse in young people. Although the latter would appear to be the more plausible possibility, both conditions have revealed a close association with RBD. Additional research studies should therefore be carried out in order to further investigate implications of Recurrent Brief Depression.

\section{References}

1. Altamura AC, Carta MG, Carpiniello B, Piras A, Maccio MV, Marcia L (1995) Lifetime prevalence of brief recurrent depression (results from a community survey). Eur Neuropsychopharmacol 5:99-102

2. American Psychiatric Association (1994) Diagnostic and statistical manual of mental disorders. 4th Edition (DSM-IV). American Psychiatric Association, Washington, DC 
3. Angst J (1994a) The history and concept of recurrent brief depression. Eur Arch Psychiatry Clin Neurosci 244(4):171-173

4. Angst J (1994b) Recurrent brief depression. In: Hippius H, Stefanis CN (eds) Research in mood disorders: an update. Hogrefe \& Huber Publishers, Seattle, pp 17-30

5. Angst J, Dobler-Mikola A (1984) The Zurich study. II. The continuum from normal to pathological depressive mood swings. Eur Arch Psychiatry Neurol Sci 234(1):21-29

6. Carlson GA, Rich CL, Grayson P, Fowler RC (1991) Secular trends in psychiatric diagnoses of suicide victms. J Affect Disord 21(2): $127-132$

7. Carta MG, Carpiniello B, Morosini PL, Rudas N (1991) Prevalence of mental disorders in Sardinia. Psychol Med 21:1061-1071

8. Carta MG, Carpiniello B, Trudu MN, Tarquini A, Rudas N (1994) La versione italiana della CIDIS: uno studio di accuratezza e riproducibilità. In: Aguglia E, Pascolo E (eds) Metropoli e Oltre. Andrea Tencati Editore. Trieste

9. Carta MG, Carpiniello B, Kovess V, Porcedda R, Zedda A, Rudas N (1995) Lifetime prevalence of major depression and dysthymia: results of a community survey in Sardinia. Europ Neuropsychopharmacol 5:103-107

10. Carta MG, Kovess V, Hardoy MC, Morosini PL, Murgia S, Carpiniello B (2002) Psychiatric disorders in Sardinian emigrants in Paris: a comparison with Parisians and Sardinians resident in Sardinia. Soc Psychiatry and Psychiatr Epidemiol 37: 112-117

11. Hasin D, Link B (1988) Age and recognition of depression: implication for a cohort effect in major depression. Psychol Med 18(3): 683-688

12. Horwarth W, Weissman MM (1995) Epidemiology of depression and anxiety disorders. In: Tsuang MT, Tohen M, Zahner GEP (eds) Textbook in psychiatric epidemiology. Wiley-Liss, New York, pp 317-344

13. Kessler RC, Walters EE (1998) Epidemiology of DSM-III-R major depression and minor depression among adolescents and young adults in National Comorbidity Survey. Depress Anxiety 7(1): 3-14

14. Kovess V (1996) Epidemiologie et santé mentale. Flammarion, Paris

15. Kovess V, Fournier L, Lesage AD, Lebigre FA, Caria A (2001) Two validation studies of the CIDIS: a simplified version of the Composite International Diagnostic Interview. Psychiatr Networks $4(1-2): 10-24$
16. Maier W, Lichtermann D, Oehrlein A, Fickinger M (1992) Depression in the community - a comparison of treated and non treated cases in two non referred samples. Psychopharmacol 106: 79-81

17. Miettinen O (1974) Confounding and effect modification. Am J Epidemiol 100:350-353

18. Montgomery SA, Montgomery D, Baldwin D, Green M (1989) Intermittent 3-day depressions and suicidal behaviour. Neuropsychobiol 22(3):128-134

19. Ohara K, Suzuki Y, Ushimi Y, Yoshida K, Ohara K (1998) Anticipation and imprinting in Japanese familial mood disorders. Psychiatry Res 79(3):191-198

20. Robins LN, Wing J, Wittchen HU, Helzer JE (1988) The Composite International Diagnostic Interview. An epidemiologic instrument suitable for use in conjunction with different diagnostic systems and in different cultures. Arch Gen Psychiatry 45: 1069-1077

21. Sartorius N, Ustun TB, Costa e Silva JA, Goldberg D, Lecrubier Y, Ormel J, Von Korff M, Wallace J, Pfohl B (1995) Age related differences in the symptomatic expression of major depression. J Nerv Ment Dis 183(1):99-102

22. Simon GE, VonKorff M, Ustun TB, Gater R, Gureje O, Sartorius N (1996) Is the lifetime risk of depression actually increasing? J Clin Epidemiol 49(9):1077-1078

23. Weissman MM, Wickramaratne P, Merikangas KR, Leckman JF, Prusoff BA, Caruso KA, Kidd KK, Gammon GD (1984) Onset of major depression in early adulthood. Increased familial loading and specificity. Arch Gen Psychiatry 41(12):1136-1143

24. Wetzel RD, Reich T, Murphy GE, Province M, Miller JP(1987) The changing relationship between age and suicides rates: cohort effect, period effect or both? Psychiatr Dev 5(3):179-218

25. Wing JK, Babor T, Brugha T (1990) SCAN: schedules for clinical assessment in neuropsychiatry. Arch Gen Psychiatry 47:586-593

26. Wittchen HU (1993) An international study of psychological problems in primary care. Preliminary report from the World Health Organization Collaborative Project on "Psychological Problems in General Health Care”. Arch Gen Psychiatry 50(10): 819-824

27. World Health Organization (1992) The ICD-10 classification of mental and behavioural disorders: clinical descriptions and diagnostic guidelines. WHO, Geneva, Switzerland 